\title{
Maximum Electrical Conductivity of Associated Lithium Salts in Solvents for Lithium-Air Batteries
}

\author{
Gabriela Horwitz, ${ }^{\dagger}$ Cristian Rodríguez, ${ }^{\ddagger}$ Matias Factorovich, ${ }^{\dagger, \S}$ and Horacio R. Corti*, ${ }^{\dagger}, \S_{(0)}$ \\ ${ }^{\dagger}$ Departamento de Física de la Materia Condensada and Instituto de Nanociencia y Nanotecnologia (INN-CONICET), Comisión \\ Nacional de Energía Atómica, Avda. General Paz 1499, B1650 San Martín, Buenos Aires, Argentina \\ ${ }^{\ddagger}$ Departamento de Química Orgánica and UMYMFOR (CONICET-UBA), Facultad de Ciencias Exactas y Naturales, and ${ }^{\S}$ Instituto \\ de Química Física de los Materiales, Medio Ambiente y Energía (INQUIMAE-CONICET), Facultad de Ciencias Exactas y \\ Naturales, Universidad de Buenos Aires, Pabellón II, Ciudad Universitaria, C1428EGA Buenos Aires, Argentina
}

\section{Supporting Information}

ABSTRACT: The choice of optimal electrolytes is crucial for improving the electrochemical performance of a lithium air battery because it determines the morphology of the discharge products in the cathode and the conductivity of the electrolyte. We have critically analyzed an important aspect related to the behavior of highly associated electrolytes, as those used in lithium-air batteries: the prediction of the concentration of maximum conductivity. Lithium triflate and lithium bis(trifluoromethyl sulfonyl)imide in glymes of low dielectric constant (1,2-di-methoxyethane and bis(2-methoxy-ethyl)ether) were used as a model of electrolytes exhibiting strong ionic clustering. The viscosity and lithium transference number of all the

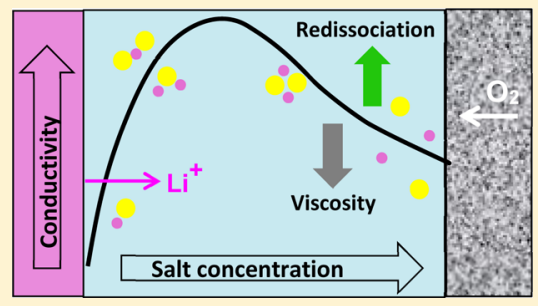
electrolytes were measured, and it was found that the correlation between the concentration of maximum conductivity and coefficient that describes the high-order dependence of the electrolyte viscosity with the concentration is no longer valid in these electrolytes because of the failure of Walden's rule, although a qualitative correlation with the salts' association constant was observed.

\section{INTRODUCTION}

Although Li-air batteries (LABs) are appealing energy storage and conversion devices because of a much larger theoretical energy density, as compared to Li-ion batteries (LIBs), their real performance is far from reaching the expected results in terms of the capacity and cyclability required for application in electric vehicles. ${ }^{1,2}$ Recent reviews on the status of LABs described the behavior of electrochemical and kinetic overpotentials. ${ }^{1,3}$ Surprisingly, the charge transport limitations during battery charge are much less severe than during discharge, mainly due to the oxygen reduction reaction (ORR) taking place at the cathode, where solid lithium peroxide $\left(\mathrm{Li}_{2} \mathrm{O}_{2}\right)$ is deposited inside the pores of the carbon cathode. The morphology and thickness of these deposits partially determine the high overpotential and low capability of the LAB because of the limited electrical conductivity of $\mathrm{Li}_{2} \mathrm{O}_{2}{ }^{4}$

There have been several attempts to describe how the maximum of the specific conductivity of lithium electrolytes depends on the type of salt and solvent because, from the practical point of view, the maximum conductivity and lithium transference number would lead to the desirable minimum Ohmic overpotential during the operation of lithium batteries. Therefore, a choice of the best electrolyte (salt/glyme couple) could be based on maximizing the lithium ionic conductivity. Moreover, for the same lithium ionic conductivity, one would prefer the salt/glyme combination that requires a lower salt concentration and the solvent that satisfies other conditions, such as low viscosity, low volatility, chemical stability, and so forth. ${ }^{5}$

The system lithium trifluoromethanesulfonate (LiTf) in bis(2-methoxy-ethyl)ether (diglyme) is the most studied of those analyzed in this work, and its ionic speciation has been previously reported by resorting to different approaches, ${ }^{6-8}$ which are described in detail in Section S1 of the Supporting Information. It follows from that analysis that ion pairs are the dominant species all over the concentration range, although its contribution tend to decrease at high concentration because of the increasing contribution of triple ions. However, this speciation behavior could not account for the reduction of molar conductivity observed in the high concentration region $^{6,8}$ neither can the speciation scheme neglecting triple ions but including LiTf dimers, as proposed by Petrowsky et al., ${ }^{6}$ leading to an unexpected increase of the ionic conductivities with increasing salt concentration (see the Supporting Information).

In fact, more sophisticated models of ion clustering ${ }^{9-11}$ lead to the conclusion that in very low dielectric constant solvents (such as glymes), an electrolyte can redissociate at high concentrations, leading to the formation of essentially free ions, as it was observed experimentally. ${ }^{12,13}$ By considering that this redissociation phenomenon would increase the molar con-

Received: January 28, 2019

Revised: April 20, 2019

Published: April 24, 2019 
ductivity at high salt concentration, we conclude that the decreasing molar conductivity of strongly associated electrolytes in the high concentration regime is determined by the increase of the system viscosity, which is not well modeled by the electrical conductivity models. Thus, another aim of this work is to establish the relationship between the conductivity and viscosity of the salt/glyme systems as a function of the salt concentration, which would allow estimating the concentration of maximum specific conductivity.

For this purpose, it is convenient to analyze the dependence of the specific conductivity with the electrolyte molar concentration, usually described by the empirical equation proposed be Casteel and Amis ${ }^{14}$

$$
\frac{\kappa}{\kappa_{\mathrm{m}}}=\left(\frac{c}{c_{\mathrm{m}}}\right)^{a} \exp \left[b\left(c-c_{\mathrm{m}}\right)^{2}-\frac{a}{c_{\mathrm{m}}}\left(c-c_{\mathrm{m}}\right)\right]
$$

where $\kappa_{\mathrm{m}}$ represents the maximum specific conductivity and $c_{\mathrm{m}}$ represents the concentration at which it occurs. Two additional adjustable parameters, $a$ and $b$, are needed to reproduce the experimental data over the entire concentration range. In spite of the fact that some attempts have been made to correlate the empirical parameters of the Casteel-Amis equation with properties of the solvent and the electrolyte, ${ }^{15}$ it is clear that eq 1 is just an empirical equation, without prediction power. Even more, the parameters obtained from the specific conductivity fit do not allow the prediction of the corresponding extremes observed in the molar conductivity at concentrations below $c_{\mathrm{m}}$ (see the Supporting Information).

There have been other attempts to describe how the maximum in the specific conductivity of lithium electrolytes depends on the system viscosity. Thus, Kondo et al. ${ }^{16}$ have proposed the following general equation for the specific conductivity, $\kappa$

$$
\kappa(c)=\left(\frac{\eta_{0}}{\eta(c)}\right) \Lambda^{0} \alpha c Q(\alpha c)
$$

where $\eta_{0} / \eta(c)$ is the ratio of solvent to solution dynamic viscosity, $\Lambda^{0}$ is the infinite dilution molar conductivity, $c$ is the salt molar concentration, $\alpha$ is the degree of dissociation, and $Q(c)$ gives the concentration dependence of the molar conductivity $(\Lambda=\kappa / c)$, given, for instance, by the FuossHsia-Fernández Prini equation. ${ }^{17}$ The dependence of the viscosity with the salt concentration is expressed by the JonesDole equation

$$
\eta(c) / \eta_{0}=1+A c^{1 / 2}+B c+D c^{2}
$$

where $A$ is the Debye-Hückel term, while $B$ and $D$ are empirical parameters. For $c>0.05 \mathrm{~mol} \mathrm{dm}^{-3}$, the term $A c^{1 / 2}$, calculated from the properties of the salt and solvent, made a negligible contribution as compared to the higher orders terms.

According to eq $2, Q(\alpha c)=(\Lambda \eta) /\left(\Lambda^{0} \eta_{0}\right)$ and, if the Walden product, $\Lambda \eta$, is almost constant all over the concentration range for the studied system, the maximum condition $\mathrm{d} \kappa / \mathrm{d} c=$ 0 leads to the simple expression ${ }^{16}$

$$
c_{\max }=D^{-1 / 2}
$$

The same equation was obtained by Chagnes et al. ${ }^{18}$ using the quasilattice theory, with $\Lambda=\Lambda^{0}-S c^{1 / 3}$. Thus, for systems where the Walden rule holds, the maximum of conductivity depends on the $D$ coefficient of the Jones-Dole equation, which is related to the viscosity enhancement at high salt concentration. The faster the viscosity increases with salt concentration, the lower the concentration at which the maximum conductivity is attained.

In this work, we will analyze the conductivity, lithium transference number, and viscosity behavior of two lithium salts, lithium trifuoromethanesulfonate (LiTf), and lithium bis(trifluoromethane sulfonyl)imide (LiTFSI), dissolved in 1,2-dimethoxyethane (DME) and diglyme, whose specific conductivities have been reported over a wide range of concentrations. ${ }^{6,8,19}$ These solvents were chosen because they exhibit good stability toward ORR intermediates, such as the superoxide anion radicals, produced upon discharge at the cathode of a LAB. For instance, Luntz and McCloskey ${ }^{1}$ concluded that the system LiTFSI/DME is one of the more stable electrolytes, whereas $\mathrm{Li}$ et al. ${ }^{20}$ indicated that LABs using $\mathrm{DME}$ as the solvent exhibit the highest yield of $\mathrm{Li}_{2} \mathrm{O}_{2}$ during discharge.

$\mathrm{Li}^{+}$transference numbers measurements in these electrolytes are scarce. The diffusion coefficients of the $\mathrm{Li}^{+}$and TFSI ${ }^{-}$have been determined in DME, diglyme, triglyme, and tetraglyme by Watanabe and co-workers ${ }^{21}$ using PGSE NMR, in the concentration range $0.5-3.5 \mathrm{M}$ at $303 \mathrm{~K}$, while Lawson and co-workers ${ }^{22}$ determined the diffusion coefficients of $\mathrm{Li}^{+}$and TFSI $^{-}$in DME between 0.5 and $2.0 \mathrm{M}$ at $298 \mathrm{~K}$ employing diffusion-ordered spectroscopy (DOSY) NMR. From the measured diffusion coefficients, they estimated the $\mathrm{Li}^{+}$ion transference number.

No information is available on the transference number of $\mathrm{Li}^{+}$in LiTf/DME and LiTf/diglyme solutions. For this reason, we have measured the diffusion coefficients of the $\mathrm{Li}^{+}$ion and the corresponding anions ( $\mathrm{Tf}^{-}$and $\mathrm{TFSI}^{-}$) in both solvents, using diffusion-ordered (DOSY) RMN spectroscopy, to determine the contribution of the lithium ion to the electrolyte conductivity.

Our aim is not to test these electrolytes under battery conditions, but use them as model systems to discuss why the assessment of the maximum specific conductivity based on eq 4 is not valid for low dielectric constant solvents, where strong ionic association leads to the breakdown of the Walden rule.

\section{EXPERIMENTAL SECTION}

2.1. Materials. Anhydrous bis(2-methoxy-ethyl)ether (Diglyme, DG, Sigma-Aldrich, $99.5 \%$ pure) and 1,2-dimethoxyethane (DME, Sigma-Aldrich, $99.5 \%$ pure) were used as received. Lithium trifuoromethanesulfonate ( $\mathrm{Li}$ triflate, Sigma-Aldrich, 99.99\%) and lithium bis(trifluoromethane sulfonyl)imide (LiTFSI, Sigma-Aldrich, 99.95\%) were dried by heating at $140{ }^{\circ} \mathrm{C}$ under vacuum for more than $12 \mathrm{~h}$. All chemicals were stored in an argon-filled MBRAUN glovebox with the oxygen content lower than $0.1 \mathrm{ppm}$, and the water content below $2 \mathrm{ppm}$. The water content of all of the solutions studied in this work content, measured using a Karl Fisher coulometer titrator (831 KFCoulometer, Metrohm), was less than $50 \mathrm{ppm}$.

2.2. Viscosity of LiTf and LiTFSI in DME and Dyglime. The kinematic viscosity $(\nu)$ of the systems LiTf/DME, LiTf/ DG, LiTFSI/DME, and LiTFSI/DG at different salt concentrations was measured with Cannon-Fenske (Ostwald modification) viscometers having constants 0.00266, 0.00632, and $0.0275 \mathrm{cSt} \mathrm{s}^{-1}$, calibrated with water, to optimize accuracy over the entire range of measurement. The viscometer was filled inside the glovebox with the solution with a given salt concentration; its noncapillary arm was sealed with a septum, 
taken out of the glovebox, and thermostatized in a water bath at $(25 \pm 0.1){ }^{\circ} \mathrm{C}$. Once the thermal equilibrium was achieved, the septum was removed, and measurements (by triplicate) were performed immediately to avoid solvent hydration.

To obtain the dynamic viscosity $(\eta=\nu / \rho)$ of the solutions, it is necessary to know their densities, $\rho$, as a function of the salt concentration. For the systems LiTFSI/DG and LiTFSI/ $\mathrm{DME}$, this property is reported in the literature, ${ }^{19}$ while for the systems LiTf/DG and LiTf/DME, it was measured using a 10 $\mathrm{cm}^{3}$ picnometer. The picnometer was filled inside the glovebox, sealed with a septum, and thermostatized at $(25 \pm$ $0.1){ }^{\circ} \mathrm{C}$ in the same water bath as the viscometers. The dependence of the solution density with salt concentration was described with a second-order polynomial (eq S14), and the fitting parameters are summarized in Table S2 (the Supporting Information).

2.3. Diffusion Coefficients of $\mathrm{Li}^{+}, \mathrm{Tf}^{-}$, and $\mathrm{TFSI}^{-}$Ions in DME and Dyglime. Diffusion-ordered (DOSY) NMR spectroscopy have been used for determining the diffusion coefficients of the solvent (glyme), $\mathrm{Li}^{+}$cation, and $\mathrm{X}^{-}$anion $\left(\mathrm{X}^{-}=\mathrm{Tf}^{-}\right.$or $\left.\mathrm{TFSI}^{-}\right)$. Each electrolyte or pure solvent was placed into a $3 \mathrm{~mm}$ (o.d.) NMR tube up to a height of $5 \mathrm{~cm}$. The length of the sample was intentionally made short so that it lay within the region of the constant magnetic field gradient and to minimize thermal convection.

The NMR measurements were performed on a Bruker AVANCE Neo 500 NMR spectrometer $\left({ }^{1} \mathrm{H}\right.$ at $500.13 \mathrm{MHz}$, ${ }^{19} \mathrm{~F}$ at $470.59 \mathrm{MHz},{ }^{7} \mathrm{Li}$ at $194.37 \mathrm{MHz}$ ) equipped with a $z$ gradient amplifier and broadband observe probe (Bruker BBFO plus-AZ Smart Probe) with $z$-axis gradient coil having a maximum gradient strength of $55 \mathrm{G} \mathrm{cm}^{-1}$. The $90^{\circ}$ pulse lengths were $12.0\left({ }^{1} \mathrm{H}\right), 13.5\left({ }^{7} \mathrm{Li}\right)$, and $15.0(19 \mathrm{~F}) \mu \mathrm{s}$. The self-diffusion coefficients were obtained at $25{ }^{\circ} \mathrm{C}$, and the gradient strength was calibrated using the known self-diffusion coefficient of the "doped water" standard sample from Bruker $\left(1.91 \times 10^{-9} \mathrm{~m}^{2} \mathrm{~s}^{-1}\right.$ at $\left.298 \mathrm{~K}\right)$.

The measurements of the diffusion coefficients of the solvent, the anion, and the lithium ion were made by ${ }^{1} \mathrm{H},{ }^{19} \mathrm{~F}$, and ${ }^{7} \mathrm{Li}$ NMR, respectively. The stimulated-echo with bipolar gradients pulse sequence was used for the diffusion measurements. Diffusion coefficients, $D$, were obtained from the decay of the echo intensity $I$ as a function of the gradient strength, $g$, to

$$
I=I_{0} \mathrm{e}^{-D \gamma^{2} \delta^{2} g^{2}\left(\Delta-\frac{\delta}{3}-\frac{\tau}{2}\right)}
$$

where $I$ is the spin-echo signal intensity, $\gamma$ is the gyromagnetic ratio, $\delta$ is the gradient pulse length, and $\Delta$ is the gradient pulses spacing. The gradient strength was increased in 16 linear steps to a maximum value of $46 \mathrm{G} \mathrm{cm}^{-1}$. Typical $\Delta$ values were 50-100, 240, and $100 \mathrm{~ms}$ for ${ }^{1} \mathrm{H},{ }^{7} \mathrm{Li}$, and ${ }^{19} \mathrm{~F}$, respectively, while $\delta$ values were $1.7-2.6,3.8-5$, and $2.4-3.5 \mathrm{~ms}$ for ${ }^{1} \mathrm{H}$, ${ }^{7} \mathrm{Li}$, and ${ }^{19} \mathrm{~F}$, respectively. A recycle delay sufficient to allow for full relaxation (i.e., $>5 T_{1}$ ) was used between each transient. All of the measured signal attenuations were well described by a straight line as expected for free diffusion. The diffusion coefficients and their errors were determined from the echo damping according to eq 5 , using Dynamic Center software provide by Bruker.

\section{RESULTS AND DISCUSSION}

3.1. Viscosity and lonic Clustering of LiTf and LiTFSI in Glymes: What Determines the Conductivity Max- imum? The viscosities of the four systems studied in this work as a function of the salt concentration are shown in Figure 1.



Figure 1. Jones-Dole plot for the viscosity at $25{ }^{\circ} \mathrm{C}:(\triangle)$ LiTf/ DME; ( $\mathbf{\Delta})$; LiTf/DG; (O) LiTFSI/DME; (๑) LiTFSI/DG.

The results can be described with the Jones-Dole eq 3, and the adjustable parameters, along with the corresponding Debye-Hückel coefficient, ${ }^{23}$ are summarized in Table 1 . It is observed that the $D$ coefficient for LiTFSI is much higher than that for LiTf in both glimes, as expected by the higher slope of the viscosity versus concentration curve for LiTFSI/DME and LiTFSI/diglyme in the concentrated region.

To test the validity of eq 4 to predict the concentration of maximum conductivity in these systems, we plotted in Figure 2a the specific conductivities at $25{ }^{\circ} \mathrm{C}$ for LiTFSI/DME, ${ }^{8,19}$ LiTFSI/DG, ${ }^{8,19} \mathrm{LiTf} / \mathrm{DG},{ }^{6,8}$ and LiTf/DME, ${ }^{8}$ over a wide range of concentrations. It should be noted that the data by Petrowsky et al. $^{6}$ for LiTf/DG were measured at room temperature, without specifying the exact value of this parameter. The increasing order of $c_{\mathrm{m}}$ is LiTFSI/diglyme $\approx$ LiTFSI/DME < LiTf/diglyme < LiTf/DME. The maximum conductivity of the LiTf/DME system has not been reached over the concentration range studied, but it is clear that it will lie above $1.4 \mathrm{~mol} \mathrm{dm}^{-3}$.

As it can be observed in Figure 2b, the molar conductivity of these associated electrolytes exhibits a more complex behavior as a function of concentration, as compared to that of the specific conductivity. In the diluted region, $\Lambda$ decreases with concentration because of the formation of neutral ion pairs, and goes through a minimum as the concentration approaches 0.01-0.02 mol dm $\mathrm{dm}^{-3}$ because above that concentration, the charged triplet ion population makes an important contribution to the charge transport. At higher concentrations, in the range $0.3-1.2 \mathrm{~mol} \mathrm{dm}^{-3}$, a maximum in molar conductivity is observed for all of the systems owing to an increase of the neutral quadruplet ionic aggregates, and also because the increasing viscosity at high salt concentrations decreases the ionic mobilities.

To assess the validity of eq 4 for predicting the concentration of maximum specific conductivity for these systems, we compare in Table 2 the experimental values of $c_{\mathrm{m}}$ along with the values calculated using eq 4. Also included in this table is the experimental $c_{\mathrm{m}}$ measured by Barthel et al. ${ }^{24}$ for the system $\mathrm{LiBF}_{4} / \mathrm{DME}$, which exhibits a strong ionic association, similar to the system LiTf/DME.

The concentration of maximum conductivity estimated through eq 4 is, in all cases, around $0.35-0.50 \mathrm{~mol} \mathrm{dm}^{-3}$ lower that the experimental ones. This behavior differs from 
Table 1. Parameters of the Jones-Dole Equation at $25{ }^{\circ} \mathrm{C}$

\begin{tabular}{lcccc}
\multicolumn{1}{c}{ system } & $A\left(\mathrm{dm}^{3 / 2} \mathrm{~mol}^{-1 / 2}\right)^{a}$ & $B\left(\mathrm{dm}^{3} \mathrm{~mol}^{-1}\right)$ & $D\left(\mathrm{dm}^{6} \mathrm{~mol}^{-2}\right)$ & $R^{2}$ \\
LiTf/DME & 0.04135 & 0.333 & 0.526 & 0.9994 \\
LiTf/DG & 0.03824 & 0.137 & 1.093 & 0.9997 \\
LiTFSI/DME & 0.04522 & -0.806 & 3.452 & 0.9970 \\
LiTFSI/DG & 0.04165 & -0.0587 & 2.434 & 0.9998
\end{tabular}

${ }^{a}$ Calculated using eq 6-9-4 from ref 23. The ionic conductivities in both glymes were taken from Table S1 in the Supporting Information Viscosities at $25{ }^{\circ} \mathrm{C}$ are $0.423 \mathrm{mPa}$ s for $\mathrm{DME}$ and $0.984 \mathrm{mPa}$ s for diglyme, while the relative dielectric constants are 7.20 for DME and 7.36 for diglyme. ${ }^{8}$

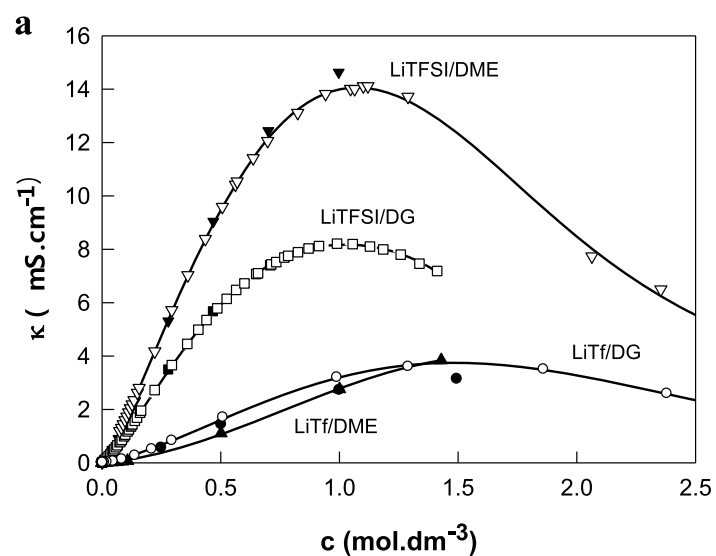

b

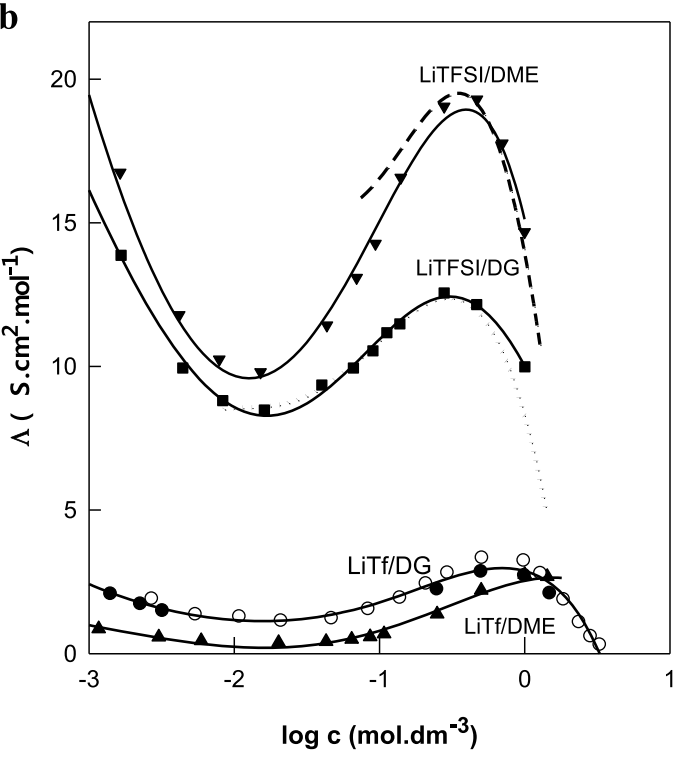

Figure 2. (a) Specific conductivity at $25{ }^{\circ} \mathrm{C}$ of: LiTFSI/DME $(\boldsymbol{\nabla})$ Horwitz et al., ${ }^{8}(\nabla)$ Brouillette et al.; ${ }^{19}$ LiTFSI/DG (ם) Horwitz et al., ${ }^{8}(\square)$ Brouillette et al.; ${ }^{19}$ LiTf/DME $(\boldsymbol{\Delta})$ Horwitz et al.; ${ }^{8}$ LiTf/DG (๑) Horwitz et al., (O) Petrowsky et al. ${ }^{6}$ (room temperature); (b) molar conductivity at $25{ }^{\circ} \mathrm{C}$. Symbols as in (a), with (----) data by Brouillette et al. ${ }^{19}$ for LiTFSI/DME; (...) data by Brouillette et al. ${ }^{19}$ for LiTFSI/DG. that found by Kondo et al. ${ }^{16}$ for the system $\mathrm{LiPF}_{6} / \mathrm{PC}$ (propylene carbonate), where the experimental $c_{\mathrm{m}}$ is $0.79 \mathrm{~mol}$ $\mathrm{dm}^{-3}$, while the calculated with eq 4 is $0.78 \mathrm{~mol} \mathrm{dm}^{-3}$. For several lithium salts $\left(\mathrm{LiBF}_{4}, \mathrm{LiPF}_{6}, \mathrm{LiAsF}_{6}\right.$, and LiTFSI $)$ in $\gamma$ butyrolactone, it was found that the experimental $c_{\mathrm{m}}$ varies between 0.97 and $1.02 \mathrm{~mol} \mathrm{dm}^{-3}$, in good agreement with the calculated $c_{\mathrm{m}}$, ranging from 0.91 to $1.15 \mathrm{~mol} \mathrm{dm}^{-3} .^{18}$

The agreement between experimental and calculated $c_{\mathrm{m}}$ is not so close in the case of LiTf or LiTFSI in the glymes studied in this work, even when the order of $c_{\mathrm{m}}$ is predicted by eq 4 , as observed in Table 2. A plausible explanation for that is the difference between the dielectric constant of DME (7.20) or diglyme (7.36), as compared with solvents with higher dielectric constant, such as propylene carbonate $(\varepsilon=64.4)$ or $\gamma$-butyrolactone $(\varepsilon=41.7)$. The Walden rule, that is the invariance of the product $\Lambda \eta$ with salt concentration, is approximately obeyed for the high-dielectric constant solvents, where the lithium salt is almost completely dissociated, leading to eq 4 , as shown in the Introduction section.

In contrast, because of the strong association of the lithium salts in the low-permittivity glymes, the Walden rule does not hold, as can be seen in Figure 3. The Walden product, $\Lambda \eta$, is not constant as a function of concentration, but it goes through a minimum for all of the studied systems and, consequently, $Q(\alpha c)=(\Lambda \eta) /\left(\Lambda^{0} \eta_{0}\right) \neq 1$ in eq 2 , and eq 4 is no longer valid. In fact, the Walden rule is not obeyed even in the diluted region $\left(c<10^{-3} \mathrm{~mol} \mathrm{dm}^{-3}\right)$ because of the strong ion pairing occurring in these solvents. In summary, the application of eq 4 to lithium salts in low dielectric constant solvents for predicting maximum conductivity concentration is invalidated by the failure of those systems to obey the Walden rule. In spite of that, there is a qualitative correlation between $c_{\mathrm{m}}$ and $D^{-1 / 2}$ that would allow us to predict that the lithium salt/ solvent system with the larger viscosity versus concentration slope in the high concentration region should exhibit the conductivity maximum at lower salt concentration.

3.2. Concentration of Maximum Conductivity and the Ionic Association. The values of the association constants, $K_{\mathrm{A}}$ and $K_{\mathrm{T}}$, determined from the conductivity data $^{8}$ using the Fuoss and Kraus procedure (eqs S6-S9) described in the Supporting Information are summarized in

Table 2. Experimental $\left(c_{\mathrm{m}}^{\mathrm{exp}}\right)$ and Calculated $\left(c_{\mathrm{m}}^{\mathrm{cal}}\right)$ Concentrations of Maximum Specific Conductivity and Association Constants of Lithium Salts in Glymes

\begin{tabular}{lcccc}
\multicolumn{1}{c}{ system } & $c_{\mathrm{m}}^{\mathrm{exp}}\left(\mathrm{mol} \mathrm{dm}^{-3}\right)$ & $c_{\mathrm{m}}^{\mathrm{cal}}\left(\mathrm{mol} \mathrm{dm}^{-3}\right)$ & $K_{\mathrm{A}}\left(\mathrm{dm}^{3} \mathrm{~mol}^{-1}\right)^{a}$ & $K_{\mathrm{T}}\left(\mathrm{dm}^{3} \mathrm{~mol}^{-1}\right)^{a}$ \\
LiTf/DME & $>1.4$ & 1.38 & $2.7 \times 10^{7}$ & 129 \\
LiTf/DG & 1.29 & 0.95 & $9 \times 10^{5}$ & 60 \\
LiTFSI/DME & 1.07 & 0.54 & $5 \times 10^{4}$ & 17 \\
LiTFSI/DG & 1.02 & 0.64 & $1.5 \times 10^{4}$ & 54 \\
LiBF $_{4} / \mathrm{DME}^{b}$ & 2.1 & & $2.3 \times 10^{7}$ & 31
\end{tabular}

${ }^{a}$ Values of $K_{\mathrm{A}}$ and $K_{\mathrm{T}}$ obtained by fitting the molar conductivity of the dilute systems to the Fuoss-Kraus equation. ${ }^{8}$ Data from Barthel et al. ${ }^{24}$ 


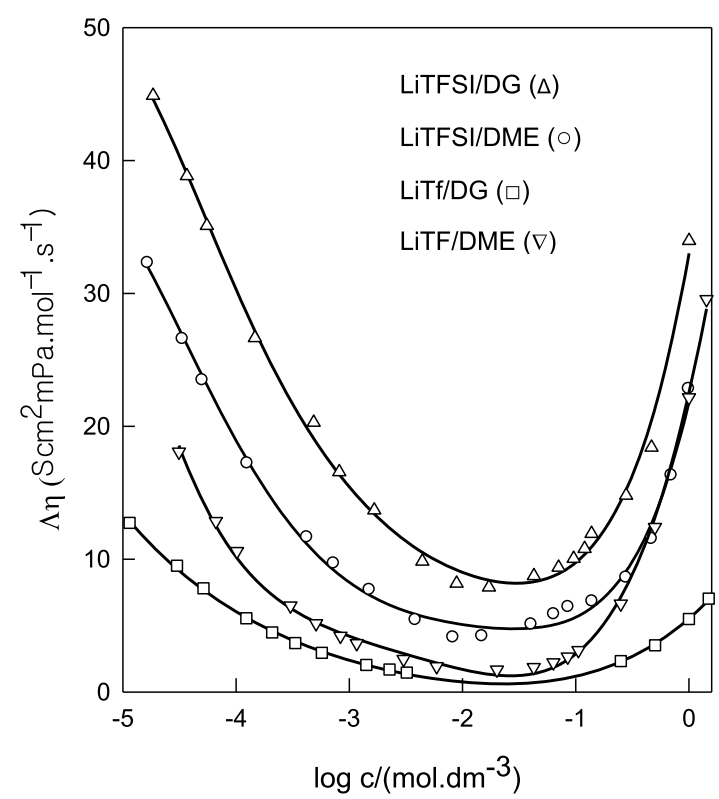

Figure 3. Walden plot at $25{ }^{\circ} \mathrm{C}$ of: LiTFSI/DG $(\triangle)$; LiTFSI/DME (O) LiTf/DG ( $\square)$; LiTF/DME $(\nabla)$. The $\Lambda \eta$ product for LiTf/DME was augmented for a factor 10 for a better comparison.

Table 2. It is observed that there is a good correlation between the strength of the ionic association and concentration of maximum conductivity: the systems which exhibit stronger ionic association, such as LiTf and $\mathrm{LiBF}_{4}$ in DME, reach the maximum conductivity at higher concentration than those with weaker association, such as LiTFSI in DME or diglyme.

The prediction of $c_{\mathrm{m}}$ is important for choosing the best electrolyte for LABs because a lower $c_{\mathrm{m}}$ implies the use of lower amount of lithium salt. However, one should also aim to maximize the specific conductivity in order of decreasing the Ohmic overpotential. Thus, one is tempted to say that the maximum conductivity will be higher for the system with weaker ionic association. However, it is inferred from Figure 2 that the system LiTFSI/DME is the one exhibiting the best maximum conductivity for a LAB, even when it is most associated than the couple LiTFSI/diglyme. The reason for that behavior is that the ionic conductivities of the charged ions $\left(\mathrm{Li}^{+}, \mathrm{X}^{-}, \mathrm{Li}_{2} \mathrm{X}^{+}\right.$, and $\left.\mathrm{LiX}_{2}^{-}\right)$are mainly determined by the viscosity of the media, and DME has almost half viscosity as compared to diglyme.

Combining both criteria, minimum amount of lithium salt and maximum conductivity, it is clear from Figure $2 \mathrm{a}$ that LiTFSI/DME is the best electrolyte of those studied in this work, including the $\mathrm{LiBF}_{4} / \mathrm{DME}$ electrolyte reported by Barthel et al., ${ }^{24}$ whose maximum conductivity is half $(7.2 \mathrm{mS}$ $\mathrm{cm}^{-1}$ ) of that found for LiTFSI/DME and would require more than double of salt concentration.

It could be argued that the relevant parameter for determining the best electrolyte is not the maximum salt conductivity, but the $\mathrm{Li}^{+}$ionic conductivity, $\lambda_{\mathrm{Li}^{+}}$. Thus, the $\mathrm{Li}^{+}$ transference number, $t_{\mathrm{Lj}}$ is required to assess $\lambda_{\mathrm{Li}}{ }^{+}=t_{\mathrm{Li}} \kappa / c$. This parameter can be obtained from the ionic diffusion coefficients reported in Table 3, by resorting to the expression

$$
t_{\mathrm{Li}^{+}}=\frac{D_{\mathrm{Li}}}{D_{\mathrm{Li}}+D_{\mathrm{X}}}
$$

The last column in Table 3 summarizes the $t_{\mathrm{Li}}$ values for the four systems studied, which in all cases are close to 0.5 , with
Table 3. Diffusion Coefficients of $\mathrm{Li}^{+}\left(D_{\mathrm{Li}}\right)$, Anion $\left(D_{\mathrm{X}}\right)$, and Solvent $\left(D_{S}\right)$, and Transference Number of $\mathrm{Li}^{+}$Ion, in $1 \mathrm{M}$ Solutions at $25{ }^{\circ} \mathrm{C}$

\begin{tabular}{lcccc}
\multicolumn{1}{c}{ system } & $\begin{array}{c}D_{\mathrm{Li}} \\
\left(10^{10} \mathrm{~m}^{-1}\right)\end{array}$ & $\left.\begin{array}{c}D_{\mathrm{X}} \\
\left(10^{10} \mathrm{~m}^{2} \mathrm{~s}^{-1}\right.\end{array}\right)$ & $\begin{array}{c}D_{\mathrm{S}_{2}} \\
\left(10^{10} \mathrm{~m}^{2} \mathrm{~s}^{-1}\right.\end{array}$ & $t_{\mathrm{Li}}{ }^{+}$ \\
LiTFSI/DG & $1.83 \pm 0.01$ & $2.04 \pm 0.02$ & $3.69 \pm 0.04$ & 0.473 \\
& & & & $0.454^{a}$ \\
LiTFSI/DME & $4.47 \pm 0.02$ & $4.36 \pm 0.04$ & $9.72 \pm 0.11$ & 0.506 \\
& & & $0.502^{a}$ \\
& & & $0.47^{b}$ \\
LiTf/DG & $2.15 \pm 0.02$ & $2.18 \pm 0.02$ & $4.98 \pm 0.05$ & 0.497 \\
LiTf/DME & $6.10 \pm 0.04$ & $6.30 \pm 0.05$ & $16.0 \pm 0.2$ & 0.492 \\
${ }^{a}$ Data from ref 21 at $30^{\circ} \mathrm{C} .{ }^{b}$ Data from ref 22. & \\
\end{tabular}

the LiTFSI/DME system exhibiting the larger $\mathrm{Li}^{+}$transference number. For the systems LiTFSI/DME and LiTFSI/DG, the agreement with previously published data ${ }^{21,22}$ is quite good. Therefore, it can be concluded that this electrolyte at concentration close to $1 \mathrm{M}$ will have the highest $\mathrm{Li}^{+}$ionic conductivity.

The diffusion coefficient order is $D_{\text {solvent }}>D_{\mathrm{X}^{-}} \approx D_{\mathrm{Li}^{+}}$for all of the electrolytes, as it has been observed for LiTFSI/DME between 0.5 and $2.0 \mathrm{M}^{22}$ (averaged $t_{\mathrm{Li}}{ }^{+}=0.48$ ). Other authors found that the diffusion order is $D_{\text {solvent }}>D_{\mathrm{TFSI}^{-}}>D_{\mathrm{Li}^{+}}$in diglyme, triglyme, and tetraglyme at concentrations up to 2 $\mathrm{M}^{22,26,27}$ implying that $t_{\mathrm{Li}}{ }^{+}<0.5$ in all of them, changing to $D_{\text {solvent }}>D_{\mathrm{Li}^{+}}>D_{\mathrm{TFSI}^{-}}$at concentrations above $2 \mathrm{M}$. Thus, in the very concentrated regime $(c \approx 3 \mathrm{M}), t_{\mathrm{Li}^{+}}$can increase, reaching values close to 0.54 , which are not high enough to compensate the decrease in the specific conductivity with increasing concentration in that region, as observed in Figure $2 b$.

It is worth noting that the maximum conductivity is not the unique descriptor in the search for the best electrolyte for LABs. Recently, Aurbach and co-workers ${ }^{25}$ observed that the degree of association of the lithium salt in the solvent is even more important than the donor number for determining the efficiency of the discharge reaction in the cathode. This is due to the fact that for highly associated salts (i.e., LiTf in DME) a "top-down" $\mathrm{Li}_{2} \mathrm{O}_{2}$ precipitation mechanism takes place, favored by the reduce affinity of the $\mathrm{Li}^{+}$ion toward the metastable superoxide anion, which can diffuse far away from the cathode surface before being associated with a $\mathrm{Li}^{+}$ion to form $\mathrm{LiO}_{2}$, which then disproportionates into $\mathrm{Li}_{2} \mathrm{O}_{2}$. Through this mechanism, the $\mathrm{Li}_{2} \mathrm{O}_{2}$ growth can expand in all directions, forming large deposits and improving the cell capacity.

According to this hypothetical discharge mechanism, the system LiTf/DME would be the best choice as the electrolyte for a $\mathrm{LAB},{ }^{8}$ but it needs to be probed experimentally if the stronger association of the LiTf/DME couple leads to a better $\mathrm{LAB}$ performance than that of LiTFSI/DME, having higher conductivity and, consequently, lower Ohmic overpotential. Also the long term stability of both electrolytes should be determined under the operation conditions of a LAB. These aspects will be analyzed in a forthcoming work.

\section{CONCLUSIONS}

Electrolytes formed by LiTf and LiTFSI dissolved in low dielectric constant glymes, such as DME and diglyme, have been analyzed as models of strongly associated electrolytes for LABs. 
For the four systems studied in this work, the electrical molar conductivities exhibit a complex dependence with salt concentration because of the presence of different ionic species that could contribute (free and triple ions) or not (ion pairs and quadruplets) to the conductivity. We suggest that the redissociation of lithium salts can occur in the high concentration regime, and the reduction of the molar conductivity of strongly associated electrolytes under that condition is mainly due to the increase of the system viscosity, which is not well modeled by the electrical conductivity models. For this reason, we focused on the relationship between the concentrations of maximum specific conductivity of these electrolytes with the coefficient $D$ of the Jones-Dole equation describing the concentration dependence of the solution viscosity.

We conclude that, even when eq 4 fails in these types of electrolytes due to the fact that the Walden rule is not obeyed, a qualitative correlation between $c_{\mathrm{m}}$ and $D^{-1 / 2}$ is observed, predicting that the conductivity maximum will occur at lower salt concentration for that lithium salt/solvent system whose viscosity increases quicker with increasing salt concentration. It was also found that the lithium salt/solvent couple which exhibits weaker ionic association reaches the maximum conductivity at lower concentration, as is the case of LiTFSI as compared to LiTf in both solvents.

In the search for the best LAB electrolyte, one should prefer the system with a lower $c_{\mathrm{m}}$, implying a lower amount of lithium salt, and that with a higher specific conductivity, to reduce the Ohmic overpotential of the battery. Comparing the systems studied in this work, LiTFSI/DME is that having the best maximum conductivity reached at a low salt concentration $\left(1.07 \mathrm{~mol} \mathrm{dm}{ }^{-3}\right)$. This couple also exhibits the highest $\mathrm{Li}^{+}$ion transference number at that concentration $\left(t_{\mathrm{Li}^{+}} \approx 0.51\right)$, which assure the best $\mathrm{Li}^{+}$ionic conductivity among the studied electrolytes.

We observed that the couple LiTFSI/DME has almost double-specific conductivity than LiTFSI/diglyme around 1 mol dm${ }^{-3}$ in spite of being more associated. The reason for that behavior is that the viscosity of DME is almost half of the viscosity of diglyme, with this parameter, instead of the speciation, being what determines the conductivity.

We have also considered the role of ionic association of the lithium salt in the solvent in relation to the mechanisms of the discharge reaction in the cathode. It has been proposed that highly associated salts (i.e. LiTf in DME) will promote a "topdown" $\mathrm{Li}_{2} \mathrm{O}_{2}$ precipitation mechanism, leading to larger deposits and, consequently, to higher $\mathrm{LAB}$ capacity. If that is the case, the couple LiTf/DME could be a better choice than the couple LiTFSI/DME, even when it exhibits a lower conductivity. Thus, this work prompts for further studies on both electrolytes to decide which one leads to a better LAB performance.

\section{ASSOCIATED CONTENT}

\section{(S) Supporting Information}

The Supporting Information is available free of charge on the ACS Publications website at DOI: 10.1021/acs.jpcc.9b00864.

Thermodynamics of ion aggregation in solvents of low dielectric constants, how the association constants can be obtained from electrical conductivity measurements, and speciation of lithium salts in glymes from conductivity and IR spectroscopy data; calculation of the ionic conductivities of lithium salts at infinite dilution using the fractional Walden rule; density of lithium salts in the studied glymes; and calculation of the extremes of the molar conductivity of strongly associated electrolytes from the Casteel-Amis equation (PDF)

\section{AUTHOR INFORMATION}

\section{Corresponding Author}

*E-mail: hrcorti@tandar.cnea.gov.ar.

ORCID $\odot$

Cristian Rodríguez: 0000-0001-8536-6842

Horacio R. Corti: 0000-0003-4718-5236

\section{Notes}

The authors declare no competing financial interest.

\section{ACKNOWLEDGMENTS}

The financial support from the Agencia Nacional de Promoción Cientifica y Tecnológica (PICT 2013-1818 and PICT 2013-2238) and CONICET (PIP 112201301 00808) is gratefully acknowledged. We thank Dr. Gerardo Burton for the use of the NMR facilities at UMYMFOR (CONICET-UBA). H.R.C. is a permanent research fellow of CONICET. G.H. thanks doctoral fellowships, and M.F. thanks postdoctoral fellowship by CONICET.

\section{REFERENCES}

(1) Luntz, A. C.; McCloskey, B. D. Nonaqueous Li-air batteries: A status report. Chem. Rev. 2014, 114, 11721-11750.

(2) Bruce, P. G.; Freunberger, S. A.; Hardwick, L. J.; Tarascon, J.-M. $\mathrm{Li}-\mathrm{O}_{2}$ and $\mathrm{Li}-\mathrm{S}$ batteries with high energy storage. Nat. Mater. 2012, $11,19-29$.

(3) Capsoni, D.; Bini, M.; Ferrari, S.; Quartarone, E.; Mustarelli, P. Recent advances in the development of $\mathrm{Li}$-air batteries. J. Power Sources 2012, 220, 253-263.

(4) Cortes, H. A.; Vildosola, V. L.; Barral, M. A.; Corti, H. R. Effect of halogen dopants on the properties of $\mathrm{Li}_{2} \mathrm{O}_{2}$ : is chloride special? Phys. Chem. Chem. Phys. 2018, 20, 16924-16931.

(5) Lee, S.-Y.; Ueno, K.; Angell, C. A. Lithium salt solutions in mixed sulfone and sulfone-carbonate solvents: A Walden plot analysis of the maximally conductive compositions. J. Phys. Chem. C 2012, 116, 23915-23920.

(6) Petrowsky, M.; Frech, R.; Suarez, S. N.; Jayakody, J. R. P.; Greenbaum, S. Investigation of fundamental transport properties and thermodynamics in diglyme-salt solutions. J. Phys. Chem. B 2006, 110, 23012-23021.

(7) Claude-Montigny, B.; Rioteau, E.; Lemordant, D.; Topart, P.; Bosser, G. Theory of ionic conduction in organic solvents and gel electrolytes: application to the system $\mathrm{DG} / \mathrm{LiCF}_{3} \mathrm{SO}_{3}$ and diacrylate/ DG/ $\mathrm{LiCF}_{3} \mathrm{SO}_{3}$. Electrochim. Acta 2001, 47, 533-541.

(8) Horwitz, G.; Factorovich, M.; Rodriguez, J.; Laria, D.; Corti, H. $\mathrm{R}$. Ionic conductivity and speciation of lithium salts in glymes: experimental and theoretical approach to electrolytes of interest for lithium-air batteries. ACS Omega 2018, 3, 11205-11215.

(9) Tani, A.; Henderson, D. A cluster theory for electrolytes. J. Chem. Phys. 1983, 79, 2390-2394.

(10) Corti, H. R.; Fernández-Prini, R. Cluster theory applied to aqueous (2:2) electrolytes over a wide concentration range. Osmotic coefficients, association and redissociation. J. Chem. Soc., Faraday Trans. 1 1986, 82, 921-932.

(11) Laría, D.; Corti, H. R.; Fernández-Prini, R. The cluster theory for electrolyte solutions. Its extension and its limitations. J. Chem. Soc., Faraday Trans. 1990, 86, 1051-1056.

(12) Seward, R. P. Electrical conductance and viscosity in the system tetra-n-butylammonium picrate-n-butyl alcohol at $91^{\circ}$. J. Am. Chem. Soc. 1951, 73, 515-517. 
(13) Pitzer, K. S.; Simonson, J. M. Ion pairing in a system continuously miscible from the fused salt to dilute solution. J. Am. Chem. Soc. 1984, 106, 1973-1977.

(14) Casteel, J. F.; Amis, E. S. Specific conductance of concentrated solutions of magnesium salts in water-ethanol system. J. Chem. Eng. Data 1972, 17, 55-59.

(15) Choquette, Y.; Brisard, G.; Parent, R.; Brouillette, D.; Perron, G.; Desnoyers, J. E.; Armand, M.; Gravel, D.; Slougui, N. Sulfamides and glymes as aprotic solvents for lithium batteries. J. Electrochem. Soc. 1998, 145, 3500-3507.

(16) Kondo, K.; Sano, M.; Hiwara, A.; Omi, T.; Fujita, M.; Kuwae, A.; Iida, M.; Mogi, K.; Yokoyama, H. Conductivity and solvation of $\mathrm{Li}^{+}$ions of $\mathrm{LiPF}_{6}$ in propylene carbonate solutions. J. Phys. Chem. B 2000, 104, 5040-5044.

(17) Fernández-Prini, R. Conductance of electrolyte solutions. A modified expression for its concentration dependence. Trans. Faraday Soc. 1969, 65, 3311-3313.

(18) Chagnes, A.; Carré, B.; Willmann, P.; Lemordant, D. Modeling viscosity and conductivity of lithium salts in $\gamma$-butyrolactone. J. Power Sources 2002, 109, 203-213.

(19) Brouillette, D.; Perron, G.; Desnoyers, J. E. Apparent molar volume, heat capacity, and conductance of lithium bis(trifluoromethylsulfone)imide in glymes and other aprotic solvents. J. Solution Chem. 1998, 27, 151-182.

(20) Li, Y.; Wang, X.; Dong, S.; Chen, X.; Cui, G. Recent advances in non-aqueous electrolyte for rechargeable $\mathrm{Li}_{-} \mathrm{O}_{2}$ batteries. $A d v$. Energy Mater. 2016, 6, 1600751.

(21) Zhang, C.; Ueno, K.; Yamazaki, A.; Yoshida, K.; Moon, H.; Mandai, T.; Umebayashi, Y.; Dokko, K.; Watanabe, M. Chelate effects in glyme/lithium bis(trifluoromethansulfonyl) amide solvate ionic liquids. I. Stability of solvate cations and correlation with electrolyte properties. J. Phys. Chem. B 2014, 118, 5144-5153.

(22) Liyana-Arachchi, T. P.; Haskins, J. B.; Burke, C. M.; Diederichsen, K. M.; McCloskey, B. D.; Lawson, J. W. Polarizable molecular dynamics and experiments of 1,2- dimethoxyethane electrolytes with lithium and sodium salts: Structure and transport properties. J. Phys. Chem. B 2018, 122, 8548-8559.

(23) Harned, H. S.; Owen, B. B. The Physical Chemistry of Electrolyte Solutions; Reinhold Pub. Co.: New York, 1950; p 176.

(24) Barthel, J.; Gerber, R.; Gores, H.-J. The temperature dependence of the properties of electrolyte solutions. VI. Triple ion formation in solvents of low permittivity exemplified by $\mathrm{LiBF}_{4}$ solutions in dimethoxyethane. Ber. Bunsen-Ges. Phys. Chem. 1984, $88,616-622$.

(25) Sharon, D.; Hirsberg, D.; Salama, M.; Afri, M.; Frimer, A. A.; Noked, M.; Kwak, W.; Sun, Y.-K.; Aurbach, D. Mechanistic role of $\mathrm{Li}^{+}$ dissociation level in aprotic $\mathrm{Li}-\mathrm{O}_{2}$ battery. ACS Appl. Mater. Interfaces 2016, 8, 5300-5307.

(26) Ueno, K.; Yoshida, K.; Tsuchiya, M.; Tachikawa, N.; Dokko, K.; Watanabe, M. Glyme-lithium salt equimolar molten mixtures: concentrate solutions or solvate ionic liquids? J. Phys. Chem. B 2012, $116,11323-11331$.

(27) Hayamizu, K.; Akiba, E.; Bando, T.; Aihara, Y. 1H, 7Li, and 19F nuclear magnetic resonance and ionic conductivity studies for liquid electrolytes composed of glymes and polyetheneglycol dimethyl ethers of $\mathrm{CH}_{3} \mathrm{O}\left(\mathrm{CH}_{2} \mathrm{CH}_{2} \mathrm{O}\right)_{\mathrm{n}} \mathrm{CH}_{3} \quad(\mathrm{n}=3-50)$ doped with $\mathrm{LiN}$ $\left(\mathrm{SO}_{2} \mathrm{CF}_{3}\right)_{2}$. J. Chem. Phys. 2002, 117, 5929-5939. 